TI 2012-014/3

Tinbergen Institute Discussion Paper
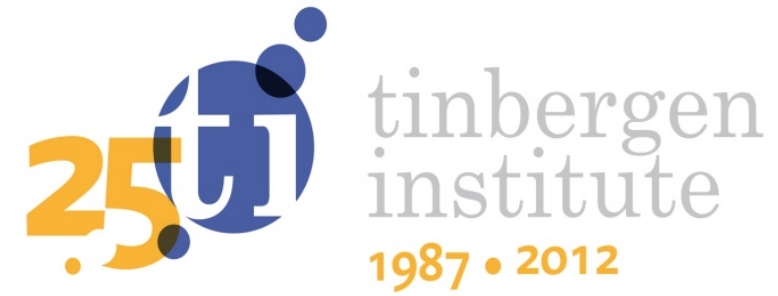

\title{
Multilevel Approaches and the Firm- Agglomeration Ambiguity in Economic Growth Studies
}

Frank G. van Oort ${ }^{1}$

Martijn J. Burger ${ }^{2}$

Joris Knoben ${ }^{3}$

Otto Raspe 4

' Department of Economic Geography, Utrecht University;

2 Erasmus School of Economics, Erasmus University Rotterdam, and Tinbergen Institute;

3 Department of Organization Studies, Tilburg University;

${ }_{4}^{4}$ Netherlands Environmental Assessment Agency. 
Tinbergen Institute is the graduate school and research institute in economics of Erasmus University Rotterdam, the University of Amsterdam and VU University Amsterdam.

More TI discussion papers can be downloaded at http://www.tinbergen.nl

Tinbergen Institute has two locations:

Tinbergen Institute Amsterdam

Gustav Mahlerplein 117

1082 MS Amsterdam

The Netherlands

Tel.: +31(0)205251600

Tinbergen Institute Rotterdam

Burg. Oudlaan 50

3062 PA Rotterdam

The Netherlands

Tel.: +31(0)10 4088900

Fax: $+31(0) 104089031$

Duisenberg school of finance is a collaboration of the Dutch financial sector and universities, with the ambition to support innovative research and offer top quality academic education in core areas of finance.

DSF research papers can be downloaded at: http://www.dsf.nl/

Duisenberg school of finance

Gustav Mahlerplein 117

1082 MS Amsterdam

The Netherlands

Tel.: +31(0)20 5258579 


\title{
Multilevel Approaches and the Firm-Agglomeration Ambiguity in Economic Growth Studies
}

\author{
Frank G. van Oort ${ }^{1}$, Martijn J. Burger ${ }^{2}$, Joris Knoben ${ }^{3}$ \& Otto Raspe ${ }^{4}$
}

\begin{abstract}
Empirical studies in spatial economics have shown that agglomeration economies may be a source of the uneven distribution of economic activities and economic growth across cities and regions. Both localization and urbanization economies are hypothesized to foster agglomeration and growth, but recent meta-analyses of this burgeoning body of empirical research show that the results are ambiguous. Recent overviews show that this ambiguity is fuelled by measurement issues and heterogeneity in terms of scale of time and space, aggregation, growth definitions, and the functional form of the models applied. Alternatively, in this paper, we argue that ambiguity may be due to a lack of research on firm-level performance in agglomerations. This research is necessary because the theories that underlie agglomeration economies are microeconomic in nature. Hierarchical or multilevel modeling, which allows micro levels and macro levels to be modeled simultaneously, is becoming an increasingly common practice in the social sciences. As illustrated by detailed Dutch data on firm-level productivity, employment growth and firm survival, we argue that these approaches are also suitable for reducing the ambiguity surrounding the agglomeration-firm performance relationship and for addressing spatial, sectoral and cross-level heterogeneity.
\end{abstract}

Keywords: agglomeration economies, micro-macro link, multilevel analysis, productivity JEL classification: C21, O18, R1

\footnotetext{
${ }^{1}$ Corresponding author: Department of Economic Geography, Utrecht University, P.O. Box 80115, NL-3508 TC, Utrecht, The Netherlands. E-mail: f.vanoort@uu.nl.

${ }^{2}$ Department of Applied Economics, Erasmus University Rotterdam and Tinbergen Institute

${ }^{3}$ Department of Organization Studies, Tilburg University

${ }^{4}$ Netherlands Environmental Assessment Agency
} 


\section{The Firm in Agglomeration Studies: The Missing Link?}

Economic growth processes occur in urban areas and industrial clusters. Therefore, urban and regional planners, geographers and economists alike are interested in the forces that create, shape and maintain concentrations of economic activities. Since the early 1990s, a large body of empirical literature has emerged in the field of regional science and urban economics. This literature examines whether spatial circumstances give rise to agglomeration economies external economies from which firms can benefit through co-location - that endogenously induce localized economic growth (Glaeser et al. 1992, Henderson et al. 1995, Combes 2000, Rosenthal and Strange 2003, Brülhart and Mathys 2008). The literature argues that externalities or spillovers occur if an innovation or growth improvement implemented by a certain enterprise increases the performance of other enterprises without requiring the benefiting enterprise to pay (full) compensation. A particularly novel feature in this literature is the combination of traditional urban economics and regional science literature with new growth theory, as formulated by Romer (1986) and Lucas (1988). In their survey of the empirical literature on the benefits of agglomeration, Rosenthal and Strange (2004) point out that the elasticity of productivity to city and industry size typically ranges from $3 \%$ to $8 \%$. However, a series of recent overview papers and meta-analyses show that the effects of agglomeration economies on localized economic growth generally differ across sectors, space, and time (Rosenthal and Strange 2004, Van Oort 2007, De Groot et al. 2009, Melo et al. 2009, Beaudry and Schiffauerova 2009, Puga 2010). Despite the complex and nuanced method of conceptually linking spillovers with growth and cities, an ever-growing body of empirical literature on urban externalities remains inconclusive on the exact agglomeration circumstances that optimally enhance growth. The missing link that leads to the ambiguity in the research results on agglomeration economies may be the relationship between agglomeration economies and individual firm performance. Although early studies examined the importance of firm-level performance in agglomerated contexts (Taylor and Asheim 2001, Dicken and Malmberg 2001), until recently, the firm-level has not been treated systematically in urban economics and spatial econometrics. Even in the strategic management literature, in which the core purpose is to explain differences in firm performance, this issue has received scant attention (McCann and Folta 2008).

A remarkable issue in the literature relates to the fact that many studies understand spatially bounded externalities as related to an enterprise's geographical or network contexts rather than to internal firm performance. Relatively little is known about the importance of 
agglomeration economies to the performance of firms (Acs and Armington 2004, Martin et al. 2008). This gap is remarkable because the theories that underlie agglomeration economies are microeconomic in nature (Brakman et al. 2009). Many empirical studies on agglomeration use aggregated data, with cities or city-industries as the basic reference unit. These studies provide only limited insights and weak support for the effects of agglomeration economies on firm performance. Regional-level relationships are not necessarily reproduced at the firm level because information on the variance between firms is lost when aggregated regional-level data are used. Hence, even if regions endowed with a greater number of agglomeration economies grow faster, this conclusion cannot be generalized to firms. In the social sciences, this micro-macro problem is referred to as the "ecological fallacy" (Robinson 1950) or the "cross-level fallacy" (Alker 1969). In addition, agglomeration effects found in area-based studies may be purely compositional (Macintyre et al. 1993). For example, the strategic management literature often argues that large firms are more likely to grow compared to small firms due to internal economies of scale. Hence, a location may grow rapidly due to the concentration of large firms rather than the localization of externalities or the external economies of scale. A similar issue is addressed in the work of Combes et al. (2008) and Mion and Naticchioni (2009) on spatial sorting and spatial wage disparities. Similarly, Baldwin and Okubu (2006) show that the agglomeration of productive firms may simply be the result of a spatial selection process in which more productive firms are drawn to dense economic areas. For this reason, it remains unclear whether geographical differences are an artifact of location characteristics (e.g., agglomeration economies) or are simply caused by differences in business and economic composition. This endogeneity problem makes it even more difficult to draw inferences about firms when using cities or regions as the lowest unit of analysis (Ottaviano 2011). Continuous space modeling offers promising perspectives for solving these issues (Duranton and Overman 2005, Arbia 2001), but some aspects can be better addressed using multilevel modeling.

To overcome the apparent impasse in the measurement and interpretation of agglomeration externalities, micro-economic and behavioral conceptualizations are needed. In particular, recent concepts introduced in evolutionary economic geography and in strategic management dynamics are promising for explaining growing firms and organizations in cities because they address the heterogeneity in the actors involved, spatial scale, selection and survival, and time and path dependency (Frenken et al. 2007, McCann and Van Oort 2009, McCann and Folta 2008). Accompanying research methods that seriously consider micromacro linkages of firms in their individual spatial and sectoral contexts are needed for this 
purpose as well (Duranton and Puga 2005, Briant et al. 2010). Recently, two strands of literature have focused on the micro-macro relationships of firms in their relevant contexts using multilevel analysis. On the one hand, urban economics and spatial econometrics consider the connection between hierarchical multilevel models and the standard spatial econometric specifications. There are limitations and difficulties with multilevel modeling in relation to spatial econometrics, such as the incorporation of spatial dependence within and between hierarchical levels of analysis and the relationship with sectoral heterogeneity (Carrada and Fingleton 2011). On the other hand, strategic management studies increasingly introduce multilevel modeling to analyze the interaction between firm performance and (agglomerated) contexts (Beugelsdijk 2007). Following social sciences, hierarchical random effects or multilevel modeling, which allows the micro level and macro level to be modeled simultaneously, is becoming an increasingly common practice in strategic management and organization studies. Goldstein (2003) and Moon et al. (2005) summarize recent overviews of area-based studies in relation to multilevel modeling.

In this paper, we argue that addressing the micro-macro level heterogeneity and interrelationships - basically, questioning which types of firms profit from which types of agglomeration economies - is served by multilevel modeling. Furthermore, we argue that these insights help to clarify the agglomeration-performance ambiguity. We show that the relationship with sectoral heterogeneity or cross-level interactions can be addressed adequately. We highlight the potential of multilevel modeling in agglomeration and economic growth studies, stressing the cross-fertilization of current hierarchical modeling with the spatial econometrics literature. We do this by briefly introducing two case studies of multilevel models in a Dutch context of agglomeration economies and firm performance. These two case studies highlight the potentials and drawbacks of the research method for urban economics, economic geography and organization studies.

This paper is further structured as follows. After introducing theories on agglomeration economies in urban economics and the strategic management literature in section 2, we briefly introduce the logic and structure of multilevel modeling in section 3 . We then present the two case studies - first, a survival and growth model of newly established advanced producer service firms in the Netherlands (section 4), and second, a study of firmlevel productivity in Dutch cities (section 5). In both cases, we link firm-level performance to agglomeration circumstances. In addition to mixed-hierarchical relations at different levels, the model of new business firm survival and growth also shows a cross-classified structure: firm-level variation is related to agglomeration, sectoral and cluster (combined agglomeration 
and sectoral) contexts. In the case study of firms' productivity, we hypothesize, based on the strategic management literature, that the relationship between firm performance and agglomeration is positively moderated by medium-sized firms, but not by small or large firms. Testing for this non-linear heterogeneity using interaction effects in multilevel modeling is the main added value of the second case study. Section 6 concludes with a discussion of the usefulness of multilevel modeling in economic agglomeration studies.

\section{The Macro to Micro Link in Agglomeration Economics and Organization Studies}

\subsection{Agglomeration Economics}

The origin of the agglomeration economies concept can be traced to the end of the nineteenth century. At the fin de siècle, the neoclassical economist Alfred Marshall aimed to overturn Malthus' and Ricardo's pessimistic (but influential) predictions on the co-evolution of economic and population development. He introduced a form of localized aggregate increasing returns to scale for firms. In his seminal work, Principles of Economics (Book IV, Chapter X), Marshall (1890) mentioned a number of cost-saving benefits or productivity gains external to a firm. He argued that a firm could benefit from co-location with other firms

engaged in the same type of business. Marshall considered these agglomeration economies to be uncontrollable and difficult to regulate as well as immobile and spatially constrained.

Marshall focused on a local specialist labor pool, the role of local knowledge spillover, and the existence of non-traded local inputs. In contrast, Hoover (1948), Ohlin (1933) and Isard (1956) identified the sources of agglomeration advantages as internal economies of scale and external economies of scale in the form of localization and urbanization economies. The production cost efficiencies realized by serving large markets may lead to increasing returns to scale in a single firm. There is nothing inherently spatial in this concept, except that the existence of a single large firm in space implies a large local concentration of employment. External economies are qualitatively very different.

Due to firm size or a large number of local firms, a high level of local employment may allow for the development of external economies within a group of local firms in a sector. These are known as localization economies. The strength of these local externalities is assumed to vary, implying that they are stronger in some sectors and weaker in others (Duranton and Puga 2000). The associated economies of scale comprise factors that reduce the average cost of producing outputs in that locality. Following Marshall (1890), a spatially concentrated sector can exert a pull on (and support) a large labor pool that includes workers 
with specialized training in the given industry. Obviously, this situation reduces search costs and increases flexibility in appointing and firing employees. Moreover, a concentration of economic activity in a given sector attracts specialized suppliers to that area, which, in turn, reduces transaction costs. Finally, agglomerated firms engaged in the same sector can profit from knowledge spillover because geographic proximity to other actors facilitates the diffusion of new ideas or improvements related to products, technology and organization.

In contrast, urbanization economies reflect external economies passed to enterprises as a result of savings from the large-scale operation of the agglomeration or city as a whole. Thus, they are independent of industry structure. Localities that are relatively more populous or places that are more easily accessible to metropolitan areas are also more likely to house universities, industry research laboratories, trade associations and other knowledgegenerating institutions. The dense presence of these institutions, which are not solely economic in character but are also social, political and cultural, supports the production and absorption of knowledge, stimulating innovative behavior and differential rates of interregional growth (Harrison et al. 1997). However, areas that are too densely populated may result in a dispersion of economic activities due to pollution, crime or high land prices. In this respect, one can speak of urbanization diseconomies.

Agglomeration economies are now thought to be more complex than Marshall originally suggested. Quigley (1998), for instance, describes additional features that are embedded in the categorization but not recognized for their individual value. These include scale economies or indivisibilities within a firm, the historical rationale for the existence of productivity growth in agglomerated industries. In consumption terms, the existence of public goods leads to urban amenities. Cities function as ideal institutions for the development of social contacts, which correspond to various kinds of social and cultural externalities. Moreover, agglomeration economies may provide greater economic efficiency growth due to potential reductions in transaction costs (Martin and Ottaviano 1999). The growing importance of transaction-based explanations of local economic productivity growth is a logical outcome of the interaction between urban economies and knowledge-based service industries, and these explanations have become more important recently (Raspe and Van Oort 2011).

Studies on urban economics and externalities have increasingly used firm-level data to assess the effect of agglomeration economies on firm performance. Audretsch and Dohse (2007) find that German firms located in a knowledge-based cluster grow faster than firms located in a region that is less endowed with knowledge resources. Renski (2011) obtains that 
industrial localization and regional industrial diversity have a positive on new businesses survival in the United States. The benefits of urbanization economies are, however, limited. Henderson (2003) considers the productivity effect of employment density in a plant's own county versus neighboring counties. Using industry and time dummies, he finds that a $10 \%$ increase in employment in a plant's own county increases the productivity of a plant by $0.8 \%$ in the high-tech industry. Using French firm-level data (both manufacturing and services), Martin et al. (2011) find that doubling the size of a firm's sector increases firm productivity by $5-10 \%$. Baldwin et al. (2008) find similar results for the effect of a firm's industry size (in terms of buyer and supplier networks, labor market pooling and knowledge spillovers) on firm productivity in five broad manufacturing sectors in Canada. Andersson and Lööf (2011) find that Swedish firms located in larger regions are more productive and also become more productive. Although the relative lack of firm-level evidence in the agglomeration economics literature can mainly be ascribed to data limitations and confidentiality restrictions, its absence is nevertheless remarkable. The theories that underlie agglomeration economies are microeconomic in nature (Martin et al. 2011). In other words, agglomeration economies do not directly foster regional economic growth; they do so only indirectly, through their effect on firm performance.

\subsection{Agglomeration in Organization Studies}

During the last two decades, in addition to the proliferation of research on geographical agglomerations, firm strategy researchers have paid increasing attention to the performance implications to firms of locating in agglomerations. Early research has concentrated on positive performance effects as incentives for firms to co-locate in an effort to explain the emergence of agglomerations (Arikan 2009, Tallman et al. 2004, Bell 2005). More recently, researchers have begun to highlight possible negative performance effects (Shaver and Flyer 2000, Arikan and Schilling 2011, Knoben 2011), and a sizable amount of empirical support for these effects has emerged. The ambiguity in research results concerning the relation between firm density, clustering and firm performance due to externalities is similar to the ambiguity in the current urban economics and regional science debates. The performanceagglomeration relationship requires research with better tools and better data to reflect the transfer mechanisms between firms and their absorptive capacities. Agglomerations are not homogenous, and they vary along several dimensions. However, research on the effect of agglomeration-level heterogeneity on the performance-agglomeration relationship has been 
far from conclusive (Beaudry and Schiffauerova 2009). Furthermore, firm-level heterogeneity has been insufficiently studied in the context of the performance-agglomeration relationship (McCann and Folta 2008). Overall, the possibility that different firms may be influenced differently by different dimensions of agglomeration remains unexplored in this body of literature.

A potential theoretical solution to address firm-level heterogeneity is to examine the interactions within (agglomerated) contexts. The strategic management approach to agglomeration economies is distinguished by its focus on explaining firm-level heterogeneity in performance. This approach argues that agglomerated firms can realize the potential benefits of location in an agglomeration only to the extent that they are capable of using knowledge from co-located firms in combination with their own knowledge assets to create value (McCann and Folta 2011). Kogut and Zander (1992) argue that firms vary significantly in such "combinative capabilities". It is suggested that these variations are related to three functions of firms. The first component of a firm's combinative capabilities is its “organizing principles”, defined as the firm's ability to coordinate different parts of the organization and transfer knowledge among them. Firm size is commonly thought to be the most important proxy for this concept. For very small firms, organizing principles reside fully with the entrepreneur or the manager of the firm, whereas for larger firms, "organization" is increasingly achieved through impersonal means, such as standard operating procedures, routines, and dedicated organizational structures. The second component of a firm's combinative capabilities is its existing knowledge base. The larger a firm's existing knowledge base, the better it can assess, access, and internalize externally available knowledge. Thus, it is more likely that the net performance effect of agglomeration will be positive for the firm. The third component of a firm's combinative capabilities relates to the number of its localized connections. Firms actively and purposefully collaborate with other firms to obtain, exchange, and mutually develop resources. The benefit of collaborating with other firms in the same region emerges from the fact that geographical proximity facilitates both planned and serendipitous face-to-face interactions, which foster the exchange of tacit knowledge (Knoben and Oerlemans 2006). These ideas have rarely been tested empirically, which leads to the ambiguity in organizational studies regarding the agglomeration-firm performance relationship. Although these three factors are expected to have direct effects on firm performance, the state-of-the-art strategic management literature has focused on their moderating effects on the performance-agglomeration relationship using multilevel modeling. 


\section{The Multilevel Model}

\subsection{From Macro to Micro}

The features of agglomeration economies described above may explain why regions characterized by an agglomeration of economic activities tend to exhibit higher economic growth (McCann and Van Oort 2009). Despite the focus in the empirical literature on the relationship between agglomeration economies and regional growth as a macro-level phenomenon, the underlying theory of agglomeration contains both macro- and micro-level propositions (see Rosenthal and Strange 2004). Although these propositions begin and end at the urban or regional level, they recede at the level of the individual firm. Coleman (1990) explored this fact in his bathtub model (also known as the "Coleman boat”), concluding that system-level phenomena (e.g., agglomeration) influence system outcomes (e.g., regional economic performance) through their effect on firms' orientations and performance. In this respect, performance differences between regions cannot be perceived as a direct result of macro-economic differences between regions. Instead, they are a by-product of firms' individual behaviors.

Firms are interested in seeking agents whose production function is partly determined by the region or city in which they are embedded. This phenomenon is influenced by the opportunities (agglomeration economies) and constraints (agglomeration diseconomies) present in this external environment (Granovetter 1985, Grabher 1993). In turn, differences in opportunities and constraints across regions generate differences in firm performance and, hence, in regional performance. Firms optimize their own performance but do not strive for regional growth. This phenomenon is more explicitly described as follows (see Figure 1):

1. The region in which a firm is embedded generates opportunities and economic constraints for firms located in that region through agglomeration economies and agglomeration diseconomies (macro-to-micro transition).

2. Firms with more economic opportunities and fewer economic constraints (Proposition 1) tend to perform better in terms of their survival chances, employment growth and productivity growth (purposive action).

3. Regions containing successful firms (Propositions 1 and 2) exhibit higher economic growth. Regional performance is conceptualized as the weighted sum of the firms' performances (micro-to-macro transition).

4. Regional performance affects regional circumstances, resulting in a feedback loop. In this fashion, the model can be linked to the evolutionary development of regions. 
Two features of this theoretical model call for clarification. First, a firm's external environment consists not only of its location (physical environment) but also other components, such as the sector in which the firm is embedded. For example, firms nested within the same sector share the same technologies and are affected by the same labor market policies and product life cycle. Second, not all opportunities and constraints facing a firm are related to macro-level properties, such as initial firm size, age or entrepreneurship. However, even when constraints and resources are firm-based, the extent to which their effect is independent of the external environment remains debatable. In our two case studies, we focus on the first two propositions and examine the extent to which the macro-micro link exists in agglomeration economics.

Figure 1: Macro- and micro-level propositions: effects of regional circumstances on regional economic growth.

4

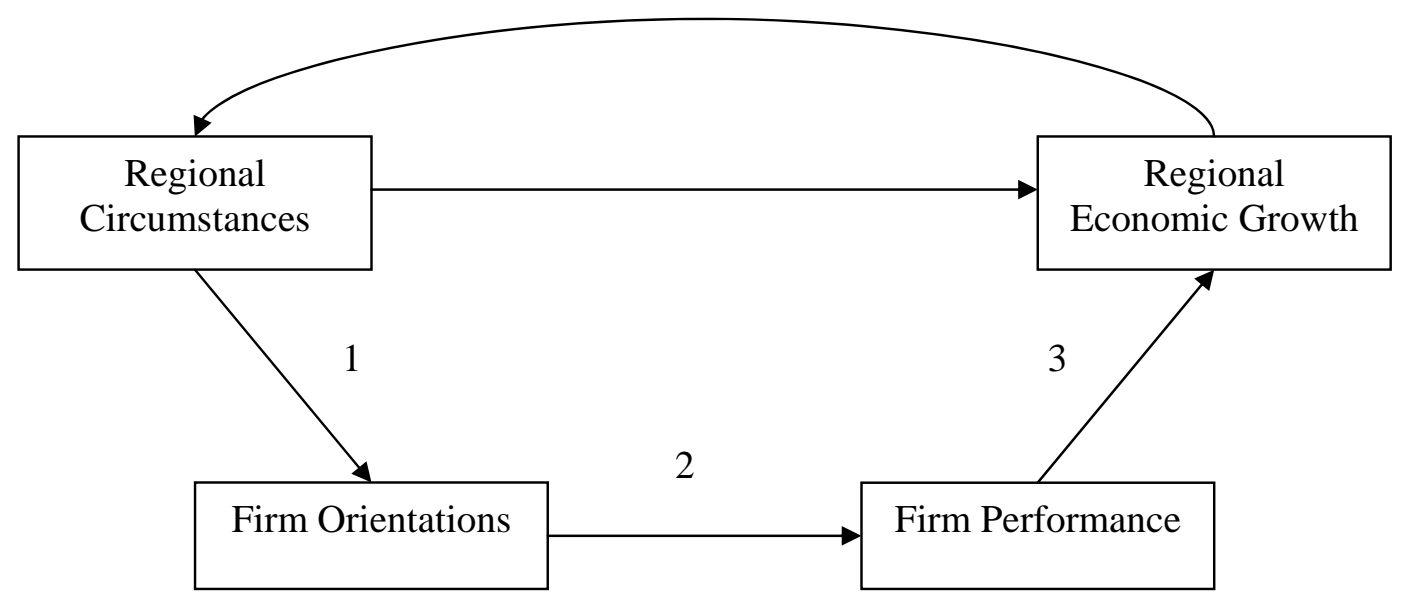

\subsection{The Multilevel Framework}

Hierarchical or multilevel modeling allows the micro level and macro level to be modeled simultaneously. Following Jones (2004), there are two distinct advantages to multilevel models. First, multilevel models offer a natural way to assess contextuality, or the extent to which a link exists between the macro level and the micro level. Applying multilevel analysis to empirical work on agglomeration begins from the simple observation that firms sharing the same external environment are more similar in their performance than firms that do not share 
the same external environment because of shared agglomeration externalities. Thus, we can assess the extent to which variance in the survival and growth rates of new establishments (case study 1, see section 4) or firm-level productivity (case study 2, see section 5) can be attributed to between-firm variance, between-area variance, or between-sector variance (McGahan and Porter 1998). With multilevel analysis, we are able to assign variability to the appropriate context (Bullen et al. 1997). Second, multilevel analysis allows us to incorporate unobserved heterogeneity into the model by including random intercepts and allowing relationships to vary across contexts through the inclusion of random coefficients. Whereas "standard" regression models are designed to model the mean, multilevel analyses focus on modeling variances explicitly. This kind of complexity can be captured in a multilevel framework through the inclusion of random coefficients (Snijders and Bosker 1999).

Hox (2002) and Goldstein (2003) provide introductions to multilevel or random-effect regression modeling. The model assumes that we have data from $J$ groups, with a different number of respondents $n_{j}$ in each group. On the respondent level, we have the outcome of respondent $i$ in group $j$, variable $Y_{i j}$. There is an explanatory variable $X_{i j}$ at the respondent level and one group-level explanatory variable, $Z_{j}$. To model these data, a separate regression model is formulated in each group:

$Y_{i j}=\beta_{0 j}+\beta_{1 j} X_{i j}+e_{i j}$

The variation of the regression coefficients $\beta_{j}$ is modeled by a group-level regression model:

$\beta_{0 j}=\gamma_{00}+\gamma_{01} Z_{j}+\mu_{0 j}$

and

$\beta_{1 j}=\gamma_{10}+\gamma_{11} Z_{j}+\mu_{1 j}$

The individual-level residuals $e_{i j}$ are assumed to have a normal distribution with mean zero and variance $\sigma_{e}^{2}$. The group-level residuals $\mu_{0 j}+\mu_{1 j}$ are assumed to have a multivariate normal distribution with an expected value of zero, and they are assumed to be independent from the residual errors $e_{i j}$. The variance of the residual errors $\mu_{0 j}$ is specified as $\sigma_{e}^{2}$, and the variances of the residual errors $\mu_{0 j}$ and $\mu_{1 j}$ are specified as $\sigma_{\mu 0}^{2}$ and $\sigma_{\mu 1}^{2}$. We write this model 
as a single regression model by substituting equations (2) and (3) into equation (1). Substitution and rearranging terms gives

$Y_{i j}=\gamma_{00}+\gamma_{10} X_{i j}+\gamma_{01} Z_{j}+\gamma_{11} X_{i j} Z_{j}+\mu_{0 j}+\mu_{1 j} X_{i j}+e_{i j}$

The segment $\gamma_{00}+\gamma_{10} X_{i j}+\gamma_{01} Z_{j}+\gamma_{11} X_{i j} Z_{j}$ in Equation 4 contains all of the fixed coefficients; it is the fixed (or deterministic) part of the model. The segment $\mu_{0 j}+\mu_{1 j} X_{i j}+e_{i j}$ in Equation 6 contains all of the random error terms; it is the random (or stochastic) part of the model. The term $X_{i j} Z_{j}$ is an interaction term that appears in the model due to modeling the varying regression slope $\beta_{1 j}$ of the respondent-level variable $X_{i j}$ with the group level variable $Z_{j}$.

Even if the analysis includes only variables at the lowest (individual) level, standard multivariate models are not appropriate. Multilevel models are needed because grouped data violate the assumption of independence of all observations (Carrada and Fingleton 2011). The amount of dependence can be expressed as the intra-class correlation (ICC) $\rho$. In the random-effect model, the ICC is estimated by specifying an empty model, as follows:

$$
Y_{i j}=\gamma_{00}+\mu_{0 j}+e_{i j}
$$

This model does not explain any variance in $Y$. It only decomposes the variance of $Y$ into two independent components: $\sigma_{e}^{2}$, which is the variance of the lowest-level errors $e_{i j}$, and $\sigma_{\mu 0}^{2}$, which is the variance of the highest-level errors $\mu_{0 j}$. Using this model, the (ICC) $\rho$ is given by the equation

$\rho=\sigma_{\mu 0}^{2} /\left(\sigma_{\mu 0}^{2}+\sigma_{e}^{2}\right)$

Our outcome variable $Y_{i j}$ is the firm performance, measured as productivity. On the regression line (3), $\beta_{0 j}$ is the usual intercept, $\beta_{1 j}$ is the usual regression coefficient (slope) for the explanatory variable, and $e_{i j}$ is the usual residual error term. The subscript $j$ is for the region, and the subscript $i$ is for individual firms. The difference with a usual regression model is that we assume that each region $j$ has a different intercept coefficient $\beta_{0 j}$ and a different slope coefficient $\beta_{1 j}$ (because the intercept and slope vary across the regions, they are often referred to as random coefficients; see Hox 2002). 


\section{Case Study 1: New Firm Survival and Growth in Advanced Producer Services}

\subsection{Agglomeration in the Advanced Producer Service Sector}

To examine the relationship between agglomeration economies and firm performance, in this first case study, we concentrate on the survival and employment growth of new establishments in the advanced producer services sector in the Netherlands. An advantage of focusing on new establishments is that these establishments are less constrained by previous decisions, such as past capital installments, which influence how they value the marginal worker and whether new employment is created (Rosenthal and Strange 2003). In the absence of many establishment-level variables, we avoid the endogeneity problems that are often present in analyses by using data on incumbent establishments.

The existing empirical literature clearly hypothesizes that new establishments benefit from agglomeration. Questioning whether agglomeration externalities bestow new entrepreneurial start-ups with any competitive advantage, Geroski (1995) argues that the growth and survival prospects of new firms depend on their ability to learn from their environment and to link changes in their strategic choices to the changing configuration of that environment. In line with Audretsch and Mata (1995), we hypothesize that survival and, subsequently, growth processes following entry are at least as important as the entry process itself. The post-entry performance of establishments reveals the selection process of markets.

Our selection of economic activities focuses on new establishments in advanced producer services sectors ${ }^{\mathrm{i}}$. Advanced business services can profit extensively from agglomeration externalities because advanced business services are among the most concentrated economic sectors in Europe (Brülhart and Traeger 2005) and these kinds of activities involve the creation, accumulation and dissemination of knowledge. Advanced producer services are characterized by their heavy reliance on professional knowledge, both codified (explicit) and tacit (implicit).

\subsection{A Mixed Hierarchical and Cross-Classified Model}

Multilevel analysis, as presented in a stylized way in section 3, is concerned with modeling hierarchically nested structures (e.g., firms located in the same region are also located in the same country due to the nesting of the two levels). However, the external environment of a firm may consist of elements that have a non-hierarchical nesting structure because they are grouped along more than one dimension or they cut across hierarchies (Goldstein 2003). For 
example, sectors are not nested in regions, and vice versa. These different facets of the external environment may explain variations in firm performance (Carrada and Fingleton 2011).

Figure 2: $\quad$ A mixed hierarchical and cross-classified model of the external environment of new establishments

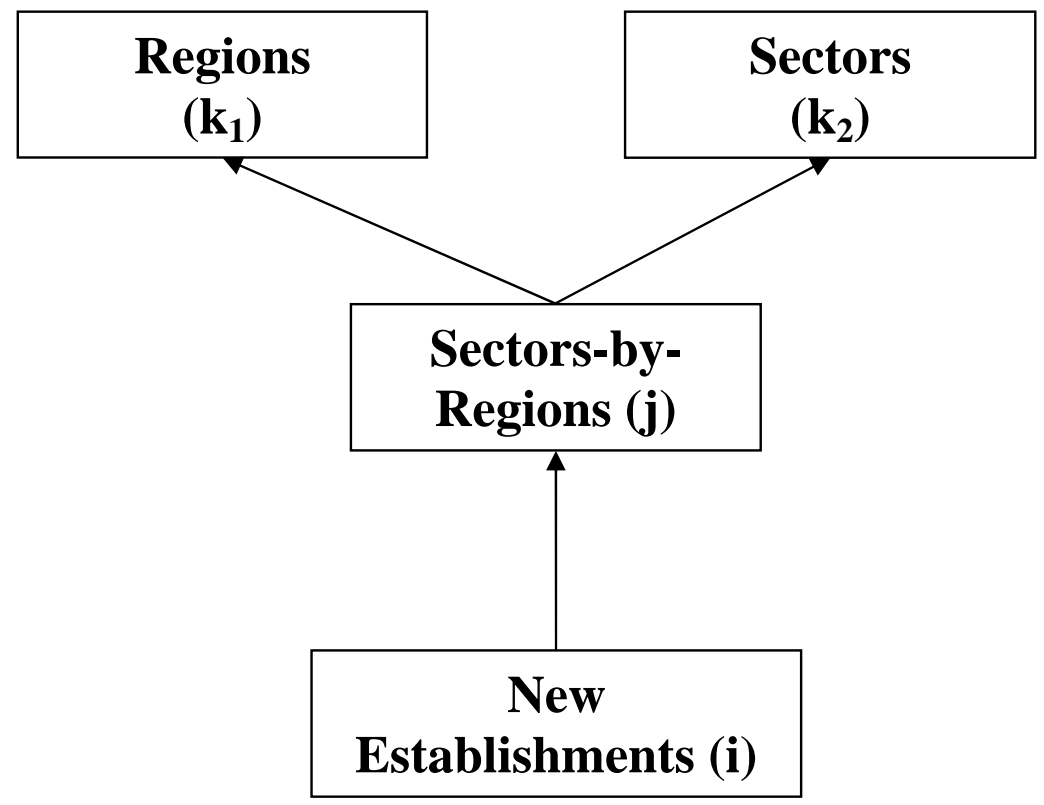

In our model, we distinguish between four classifications, first in regions (40 NUTS-3 regions in the Netherlands), second in sectors (19 sectors in the advanced producer services), third in sectors-by-regions $(40 * 19=781$ clubs $)$ and fourth in establishments of firms $(46,038$ newly founded establishments, 27,133 of which survive and grow in the first five years of existence). Firms may be affected by the region (agglomeration) in which they are located. As indicated in section 2, these location factors may be general (urbanization economies, in which all establishments in a given location are exposed to these factors) or sector-specific (localization economies, in which these factors are restricted to a subset of firms nested within a given sector in that location). However, firms may also be affected by the classification of sectors or "clubs" (sector-location combinations, see Gordon and McCann 2000). Thus, we disentangle the general location factors and the nation-wide sector-specific factors from the sector-specific factors that are spatially bounded. To illustrate this, we use a mixed hierarchical and cross-classified model (presented in Figure 2). We have a three-level 
model (with four classifications) with a random intercept for firms at the lowest level and random intercepts for regions $(k 1)$, sectors-by-regions $(j)$, and sectors $(k 2)$ at the higher levels. More formally, we estimate the following base probit model for the probability of survival $y_{i j(k 1, k 2)}$ of new establishments in the advanced producer services:

$y_{i j(k 1, k 2)}=\operatorname{Binomial}\left(n_{i j(k 1, k 2)}, \mu_{i j(k 1, k 2)}\right)$

$\operatorname{probit}\left(\mu_{i j(k 1, k 2)}\right)=X_{i j(k 1, k 2)} \beta_{0}+u_{0 j(k 1, k 2)}+v_{0 k 1}+v_{0 k 2}$

where $u_{0 j(k 1, k 2)} \sim N\left(0, \sigma_{u 0 j(k 1, k 2)}^{2}\right), v_{0 k 1} \sim N\left(0, \sigma_{v 0 k 1}^{2}\right), v_{0 k 2} \sim N\left(0, \sigma_{v 0 k 2}^{2}\right)$,

in which the probability of survival or growth of new firms $\mu_{i j(k 1, k 2)}$ is explained by the single fixed intercept term $X_{i j(k 1, k 2)} \beta_{0}$, which is the average survival or growth rate of new firms in the advanced producer services. The three separate random terms $u_{0 j(k 1, k 2)}+v_{0 k 1}+$ $v_{0 k 2}$ are related to the intercept and mirror the remaining residual variation at the higher levels. This differs from a typical regression model in that we assume that each sector-byregion $j$, region $k 1$ and sector $k 2$ has a different intercept. Note the mixed-hierarchical and cross-classified structure here: the indexing structure $\mu_{i j(k 1, k 2)}$ refers to the $i^{\text {th }}$ firm in the $j^{\text {th }}$ club, which is nested in region $k_{1}$ and sector $k_{2}$. This null model allows us to understand how to attribute variation in the probability of new establishment survival and growth to various contexts.

As indicated in section 3.2, the variance partition coefficient (VPC) measures the extent to which the probability of survival and growth of new establishments in the same club, region or sector resemble one other relative to those from new establishments in different clubs, regions or sectors. This figure may also be interpreted as the proportion of the total residual variation in survival that is due to differences between clubs, regions, or sectors. For example, the VPC for regions represents the percent of variation explained by the regionlevel differences for firm $i$ in club $j$ and sector $k 2$.

$V P C_{k 1}=\sigma_{v 0 k 1}^{2} /\left(\sigma_{u 0 j(k 1, k 2)}^{2}+\sigma_{v 0 k 1}^{2}+\sigma_{v 0 k 2}^{2}\right)$

In Equation (8), the term $\sigma_{u 0 j(k 1, k 2)}^{2}$ is the between-club variance, $\sigma_{v 0 k 1}^{2}$ is the between-region variance, and $\sigma_{v 0 k 2}^{2}$ is the between-sector variance. We assume that the probit distribution for the firm-level residual implies a variance of 1 (Goldstein 2003). 


\subsection{Adding predictor variables and cross-level interactions}

To determine the extent to which agglomeration variables explain the partitioned variability, we can add predictor variables to these classifications. More specifically, the predictors (or fixed parameters) we add here contain measures related to firm characteristics, sector-byregion characteristics and region characteristics. Because we are mainly interested in the effects of regional and sector-by-region characteristics on firm performance, we include sector fixed effects $\left(\delta_{k 2}\right)$ by including sector dummies. More formally,

$$
\begin{aligned}
& y_{i j(k 1, k 2)}=\text { Binomial }\left(n_{i j(k 1, k 2)}, \mu_{i j(k 1, k 2)}\right) \\
& \operatorname{probit}\left(\mu_{i j(k 1, k 2)}\right) \\
& \qquad \begin{array}{l}
=X_{i j(k 1, k 2)} \beta_{0}+\beta_{10} X_{1 i j(k 1, k 2)}+\sum_{j=1}^{q} \beta_{q 0} X_{q j(k 1, k 2)}+\sum_{k 1=1}^{r} \beta_{r 0} X_{r k 1}+\delta_{k 2} \\
+u_{0 j(k 1, k 2)}+v_{0 k 1}
\end{array}
\end{aligned}
$$

Where $u_{0 j(k 1, k 2)} \sim N\left(0, \sigma_{u 0 j(k 1, k 2)}^{2}\right), v_{0 k 1} \sim N\left(0, \sigma_{v 0 k 1}^{2}\right)$.

In Equation (9), the segment $\beta_{10} X_{1 i j(k 1, k 2)}+\sum_{j=1}^{q} \beta_{q 0} X_{q j(k 1, k 2)}+\sum_{k 1=1}^{r} \beta_{r 0} X_{r k 1}$ contains the predictor variables $X$ at the firm, club and region levels that enter the analysis. The subscripts $q$ and $r$ indicate the number of predictor variables included at the club and regional levels, respectively (please note that with respect to the establishment level, we only include initial firm size, $X_{1}$ ). The $\beta$ s refer to the associated regression slope terms.

Equation (9) is a random intercept model. Only the intercept varies across clubs and regions. However, parameter estimates may also vary across different sub-populations. For example, the effects of localization and urbanization economies may vary over small and large firms. This can be modeled using a cross-level interaction between firm size $\left(X_{1}\right)$ and the respective agglomeration economies. Including firm size as predictor variable at the firm level, we obtain the following Equation (10). 


$$
\begin{aligned}
& y_{i j(k 1, k 2)}=\text { Binomial }\left(n_{i j(k 1, k 2)}, \mu_{i j(k 1, k 2)}\right) \\
& \operatorname{probit}\left(\mu_{i j(k 1, k 2)}\right)=X_{i j(k 1, k 2)} \beta_{0}+\beta_{10} X_{1 i j(k 1, k 2)}+\sum_{j=1}^{q} \beta_{q 0} X_{q j(k 1, k 2)}+\sum_{k 1=1}^{r} \beta_{r 0} X_{r k 1}+ \\
& \delta_{k 2}+\sum_{j=1}^{q} \beta_{q 10} X_{1 i j(k 1, k 2)} X_{q j(k 1, k 2)}+\sum_{k 1=1}^{r} \beta_{r 10} X_{1 i j(k 1, k 2)} X_{r k 1}+u_{1 j(k 1, k 2)} X_{1 i j(k 1, k 2)}+ \\
& v_{1 k 1} X_{1 i j(k 1, k 2)}+u_{0 j(k 1, k 2)}+v_{0 k 1},
\end{aligned}
$$

where $u_{0 j(k 1, k 2)} \sim N\left(0, \sigma_{u 0 j(k 1, k 2)}^{2}\right), v_{0 k 1} \sim N\left(0, \sigma_{v 0 k 1}^{2}\right)$.

In Equation (10), $\sum_{j=1}^{q} \beta_{q 10} X_{1 i j(k 1, k 2)} X_{q j(k 1, k 2)}+\sum_{k 1=1}^{r} \beta_{r 10} X_{1 i j(k 1, k 2)} X_{r k 1}$ now represents the cross-level interactions between firm size and the club-level variables and between firm size and the region-level variables, respectively, whereas

$u_{1 j(k 1, k 2)} X_{1 i j(k 1, k 2)}+v_{1 k 1} X_{1 i j(k 1, k 2)}+u_{0 j(k 1, k 2)}+v_{0 k 1}$ represents the random part of the model. The expressions $u_{1 j(k 1, k 2)}+v_{1 k 1}$ are the random slope parameters that make the effect of firm size on the probability of survival or growth dependent on the club and region in which the firm is embedded. The cross-level interactions that aim to explain the random slopes can be interpreted as the variation of the effect of the club and region variables across small and larger firms. In the remainder of the case study, we focus on the interaction between firm size and the different agglomeration economies. However, it should be noted that the range of possible interactions is not limited to these variables.

\subsection{Data and Variables}

Data on employment at the firm level were obtained from the LISA (National Information System of Employment) database, an employment register that covers all establishments in the Netherlands for the period 1996-2006. Our first dependent variable, SURVIVAL (2000-2006), is a Boolean dummy variable measured at the level of the establishment, which takes the value 1 if a new establishment in 2000 or 2001 survived the first five years of its existence. There are 46,038 new firms in the dataset. Our second dependent variable, EMPLOYMENT GROWTH, is a Boolean dummy variable measured at the level of the firm that takes the value 1 if a firm that was newly established in 2000/01 (and surviving) grows in terms of an increase in the number of employees in the first five years of its existence. There are 27,133 surviving and growing firms in the dataset. As indicated in the theoretical framework of agglomeration economies, we focus on two types of agglomeration economies. LOCALIZATION ECONOMIES, or sector-specific scale economies, are defined at the sector-by-region level and measured as the 
concentration of own-sector employment in the region under observation. URBANIZATION ECONOMIES, or economies available to all firms in a region, are defined at the region level and measured by the concentration of total employment, which arises from urban size and density. We control at the firm level for INITIAL FIRM SIZE, measured as the natural logarithm of the number of employees in the year the firm was founded. Size represents the economies of scale available to a new establishment. By explicitly differentiating between internal and external economies of scale, we account for compositional effects. At the club level, we control for market structure with the variable COMPETITION. This is measured as the natural logarithm of the number of entries and exits in the regional sector between 2000 and 2006 divided by the number of firms in 2000 (compare Glaeser et al. 2000). Finally, at the regional level, the controls are $R \& D$ EXPENDITURES, measured as the natural logarithm of the $\mathrm{R} \& \mathrm{D}$ expenditures of firms, research institutes and government agencies in 2000, and HUMAN CAPITAL stock in a region, measured as the natural logarithm of the percentage of the workforce that was highly educated (ISCED 5-6) in 2000.

\subsection{Modeling Strategy}

We estimate six models. First, we estimate two random intercept probit models (equation 7) for survival and employment growth without including predictor variables. The variance partition coefficients are derived from these models (equation 8), which serve as a tool to indicate the extent to which location matters by explicitly disentangling the between-location variance from the between-firm and between-sector variance. These cross-classified probit models are estimated using the Markov Chain Monte Carlo algorithm using Gibbs sampling. Second, we estimate two random intercept probit models (equation 10) to assess the importance of the different types of agglomeration economies on new firm survival and employment growth. Third, we estimate two random coefficient models to assess whether the effect of agglomeration economies varies across firms of different sizes ${ }^{\mathrm{ii}}$.

Table 1 shows the proportion of the total residual variation in new firm survival and employment growth in the advanced producer services sector that is due to differences between clubs, regions, or (sub)sectors. We see that firm performance (survival and growth) is mainly affected by internal characteristics. More than $90 \%$ of the total variance is betweenfirm variance. The between-region variance is approximately 3\%, whereas the between-club variance is approximately $1 \%$. Hence, the location effect explains approximately $4 \%$ of the variation in firm performance. Although the external environment explains a relatively small 
part of the variation in firm performance, the region contributes to firm performance. The region represents a solitary factor that accounts for the enormous diversity of firms. Because we defined agglomeration economies as both regional (urbanization economies) and clubrelated (localization economies), we conclude that these externalities 'explain' approximately $3-5 \%$ of the variance in firm performance of new firms.

Table 1: Variance partition coefficients (VPCs) for the survival and employment growth of new producer service firms

\begin{tabular}{|l|c|c|}
\hline & $\begin{array}{c}\text { Model 1 } \\
\text { Survival }\end{array}$ & $\begin{array}{c}\text { Model 2 } \\
\text { Employment growth }\end{array}$ \\
\hline VPC (firm) - between-firm variance & $90.9 \%$ & $93.7 \%$ \\
\hline VPC (club) - between-club variance & $1.3 \%$ & $0.8 \%$ \\
\hline VPC (region) - between-region variance & $3.3 \%$ & $2.5 \%$ \\
\hline VPC (sector) - between-sector variance & $4.5 \%$ & $3.0 \%$ \\
\hline Total & $100 \%$ & $100 \%$ \\
\hline $\mathrm{N}$ & 46,038 & 27,133 \\
\hline
\end{tabular}

\subsection{Agglomeration Economies, New Firm Survival and Employment Growth}

Table 2 shows the results of our further model estimates. Model 3 is the probit model on survival, and model 4 the probit model on unconditional employment growth for the new firms that survived in the first five years of existence. ${ }^{\text {iii }}$ With respect to firm size and survival opportunities (due to downscaling possibilities), we find a small positive and significant effect. On average, a 1\% increase in firm size increases the likelihood of survival by 0.012 percentage points. The effect we obtain may be small because our 'sample' of new firms mainly consists of smaller firms and the heterogeneity of size in relation to survival is relatively low. However, with respect to the employment growth of new firms, we find a much larger and significant relationship: a 1\% increase in size increases the likelihood of survival by 0.32 percentage points. This is in line with arguments on the 'economies of scale' in the literature, which emphasize that small firms must overcome cost disadvantages (in contrast to larger firms). 'Internal economies of scale' cause a reduction in per-unit costs over the number of units produced, efficiency advantages and, hence, growth potential.

We now turn to the effect of the agglomeration economies on new firm performance in the advanced producer services sector. From the previous section, we see evidence of a 'solitaire spatial effect'. However, the effect of location on firm performance is complex. First, the concentration of own-sector employment (localization economies) has a small, positive effect on new firm survival but no effect on the unconditional employment growth. 
A $1 \%$ increase in own-sector employment increases the probability of survival by 0.09 percentage points. The urban density effect, stemming from urbanization economies, has a much higher impact on new firm performance in the advanced producer services. New firms located in dense urban regions experience higher survival rates and employment growth. A $1 \%$ increase in urban density increases the probability that a firm in the advanced producer services sector will survive the first five years by 0.28 percentage points and increases the probability of employment growth in the first five years by 0.17 percentage points. We conclude that new firms in the advanced producer services sector have fewer difficulties surviving in cities. Moreover, when they succeed and survive, their growth rates are significantly higher due to this 'concentration of total employment' effect.

Table 2: Multilevel probit on new firm survival and employment growth

\begin{tabular}{|c|c|c|}
\hline & $\begin{array}{c}\text { Model } 3 \text { - PROBIT } \\
\text { survival }\end{array}$ & $\begin{array}{l}\text { Model } 4-P R O B I T \\
\text { employment growth }\end{array}$ \\
\hline \multicolumn{3}{|l|}{ Fixed part } \\
\hline Intercept & $0.153(.659)$ & $-1.739(.509)^{* * *}$ \\
\hline Initial Establishment Size (In) & $0.013(.007)^{*}$ & $0.302(.010) * * *$ \\
\hline Localization Economies (ln) & $0.094(.053)^{*}$ & $0.014(.027)$ \\
\hline Competition (ln) & $-0.085(.054)$ & $-0.125(.045)^{* * *}$ \\
\hline Urbanization Economies (ln) & $0.277(.102)^{* * *}$ & $0.174(.074)^{* *}$ \\
\hline Human Capital (ln) & $-0.129(.146)$ & $-0.034(.132)$ \\
\hline$R \& D$ Expenditures $(\ln )$ & $-0.064(.035)^{*}$ & $0.019(.027)$ \\
\hline \multicolumn{3}{|l|}{ Random part } \\
\hline$u_{o j k 1}$ & $0.013(.002)$ & $0.006(.003)$ \\
\hline$v_{o k 1}$ & $0.023(.006)$ & $0.013(.004)$ \\
\hline Sector fixed effects & Yes & Yes \\
\hline Mundlak correction & Yes & Yes \\
\hline Observations & 46,038 & 27,133 \\
\hline
\end{tabular}

\subsection{Varying Effects of Agglomeration across Small and Large Firms}

Focusing on the effect of agglomeration externalities, we analyze whether there is a positive relationship between agglomeration economies and firm performance in terms of new firm survival and employment growth. This relationship might not be fixed in all regions ('fixed' meaning that it does not vary over regions). We argue that some firms (based on firm-specific characteristics) profit more than others, or that externalities only appear for some types of 
firms. In this section, we test for 'cross-level interaction effects', interactions between variables measured in hierarchically structured data on different levels (Hox 2002). We focus on initial firm size and analyze the possibility that agglomeration economies are mainly effective for larger start-ups.

It appears that initial firm size has a significant slope variance (the basic underlying condition for the existence of cross-level interaction effects). Table 3 shows the results of the random coefficient models, in which we allowed for the possibility that the effect of initial firm size can vary from region to region (regions have different slopes), including an interaction effect on size and localization and urbanization economies. The random part in Table 3 shows that the covariance between the region's intercept and slope is significant and positive. This positive covariance suggests that a higher intercept is associated with a higher slope. In other words, larger firms perform better in some regions, or their smaller counterparts perform less well in other regions. Concerning survival, we find that the interaction effects between initial establishment size and localization and urbanization economies are significant and positive. This means that larger start-ups profit more from own-industry and urban density. We find the opposite for employment growth: the interaction effect between initial establishment size and localization economies is significant but negative, whereas the interaction-effect between initial establishment size and urbanization economies is not significant. The first finding means that smaller start-ups profit more from proximity to a concentration of own-sector employment than do their larger counterparts. New firms with differing start-up sizes do not profit differently from urbanization economies in relation to employment growth. 
Table 3: Multilevel probit on new firm survival and employment growth

\begin{tabular}{|c|c|c|}
\hline & $\begin{array}{c}\text { Model } 5 \text { - PROBIT } \\
\text { survival }\end{array}$ & $\begin{array}{l}\text { Model } 6 \text { - PROBIT } \\
\text { employment growth }\end{array}$ \\
\hline \multicolumn{3}{|l|}{ Fixed part } \\
\hline Intercept & $-0.041(.636)$ & $-1.483(.476) * * *$ \\
\hline Initial Establishment Size (ln) & $-0.138(.131)$ & $0.157(.182)^{*}$ \\
\hline Localization Economies (ln) & $0.083(.054)$ & $0.023(.027)$ \\
\hline Competition (ln) & $-0.087(.054)$ & $-0.095(.043)^{* *}$ \\
\hline Urbanization Economies (ln) & $0.254(.098)^{* * *}$ & $0.173(.064)^{* *}$ \\
\hline Human Capital (ln) & $-0.181(.138)$ & $0.046(.120)$ \\
\hline$R \& D$ Expenditures $(\ln )$ & $-0.064(.033)^{*}$ & $0.007(.024)$ \\
\hline Est. Size * Localization Economies & $0.022(.013)^{*}$ & $-0.031(.018)^{*}$ \\
\hline Est. Size * Urbanization Economies & $0.051(.021)^{* *}$ & - \\
\hline \multicolumn{3}{|l|}{ Random part } \\
\hline$u_{o j k 1}$ & $\begin{array}{l}0.015 \\
(.003)\end{array}$ & \begin{tabular}{|l|}
0.005 \\
$(.003)$ \\
\end{tabular} \\
\hline$u_{1 j k 1}$ & $\begin{array}{l}0.009 \\
(.002)\end{array}$ & $\begin{array}{l}0.024 \\
(.005)\end{array}$ \\
\hline$v_{0 k 1}$ & $\begin{array}{l}0.033 \\
(.008)\end{array}$ & $\begin{array}{l}0.021 \\
(.006)\end{array}$ \\
\hline$v_{1 k 1}$ & $\begin{array}{l}0.006 \\
(.002) \\
\end{array}$ & $\begin{array}{l}0.007 \\
(.003) \\
\end{array}$ \\
\hline Sector fixed effects & Yes & Yes \\
\hline Mundlak correction & Yes & Yes \\
\hline Observations & 46,038 & 27,133 \\
\hline
\end{tabular}

The first case study focuses on the determinants of the survival and growth of new firms in the advanced producer services sector in the Netherlands. Employing a mixed hierarchical and cross-classified probit regression, we introduce a model of firm survival and growth that is specific to the characteristics of the internal and external environment of a firm. This external environment may consist of several components, such as the firm's location, sector or club (location-by-sector). This case study shows that 1 ) the location effect can be carefully disentangled from the firm and sector effect, and 2) we can analyze whether firms benefit from agglomeration economies asymmetrically. Similar insights are difficult to obtain with other estimation methods. 


\section{Case Study 2: Agglomeration, Organization and Productivity of Firms}

\subsection{Non-linear Heterogeneity in Micro-Macro relations}

In our second case study, we present a multilevel analysis that extends the arguments regarding the agglomeration performance relationship with insights from the strategic management literature. Specifically, we argue that agglomerations are heterogeneous along two spatial dimensions, urbanization and localization (level of specialization). Similar to the previous case study, it is hypothesized that these dimensions give rise to orthogonal performance implications for firms. In line with the hypotheses postulated in section 2.2, we test whether a firm's combinative capabilities, as manifested in its organizing principles which are measured for this paper, rather simply, by firm size - are related to firm productivity in agglomerated contexts. We again test our hypotheses by estimating multilevel models, this time with non-linear interaction effects between the agglomeration and firmlevel variables, using survey data from a sample of Dutch firms. The results suggest that the effects of different dimensions of agglomeration on firm performance are strongly and nonlinearly moderated by a firm's combinative capabilities. The moderation effect is not uniform across either the two different agglomeration dimensions or the different sizes of firms.

A central concept in strategic management theories concerns a firm's ability to coordinate different parts of the organization and transfer knowledge among them (Kogut and Zander 1992, McCann and Folta 2011). Size plays a significant role in a firm’s organizing principles. For small firms, organizing principles are located in the entrepreneur or the manager of the firm, whereas for larger firms, “organization” is increasingly achieved through impersonal means, such as standard operating procedures, routines, and dedicated organizational structures. The literature suggests that inertia and rigidity are associated with larger firm size as well (Miller and Chen 1994). Due to the complexity of large firms, actions between large numbers of people must be coordinated and managed, resulting in institutionalized and rigid rules and procedures. These structures may reduce large firms' openness to their environment as well as their flexibility, consequently preventing them from finding and effectively integrating externally available resources into their existing resources. The literature also emphasizes the inability of very small firms to internalize externally available resources (Deeds and Rothearmel 2003). Full reliance on one or several individuals to assess, access, and internalize externally available resources without procedures, routines 
or dedicated units to aid such processes is likely to result in missed opportunities and the lack of capability to utilize external resources.

The above arguments suggest that when a firm is too large or too small, it is unlikely to fully benefit from the positive performance effects of agglomeration. For such firms, we expect the net agglomeration effect to be negative. We thus hypothesize that the relationship between firm performance and agglomeration is positively moderated by medium-sized firms but not by small or large firms. Testing this non-linear heterogeneity using interaction effects in multilevel modeling is the main added value of this second case study.

\subsection{Data and Variables}

At the firm level, we use data from an establishment-level survey that was conducted in 2005 in the Netherlands. We opted for a survey in this case study rather than relying on secondary data because our research goal requires detailed productivity data at the establishment level (rather than the consolidated firm level) from a wide range of industries and size classes. Existing databases fail to meet these requirements. The survey targeted firms in the manufacturing and business services industries. We excluded retail and customer-related services because these predominantly follow the distribution of the population and are therefore unlikely to exhibit distinct and geographically differentiated patterns of agglomeration.

Within the manufacturing and business services industries in the selected regions, we used a random stratified sample from the LISA database (see section 4.4), taking into account firm size, industry and region (i.e., municipalities) ${ }^{\mathrm{iv}}$. Ultimately, the size of the sample was 28,637 firms. The survey was targeted at directors or owners at the establishment level. After a round of reminders, the response rate was approximately $7 \%(\mathrm{~N}=2009)$. The final sample is representative of the stratification by region, size and industry. Table 4 outlines the population and response rates.

Previous research on the relationship between agglomeration effects and firm performance utilized a wide variety of performance indicators. Some of these measures are highly context dependent. Performance measures that are frequently used in cross-industry studies are employment growth and productivity (Beaudry and Schiffauerova 2009). Employment growth, however, has been criticized as a performance measure for wellperforming firms investing in labor-saving innovations, particularly in the manufacturing industries. We adopt the level of productivity of the firm, defined as the added value of a firm 
per employee, as our performance measure. The firm's added value is determined as the yearly gross turnover in 2004 minus purchases for that year (all intermediate goods and service needed in the production process of the firm). The added value includes the firm's taxes, subsidy, wages, and profits. Productivity is determined by dividing the added value at the firm level by the number of employees of the firm (again measured for 2004).

\section{Table 4: Geographical Breakdown of Population and Survey Response}

\begin{tabular}{lccc}
\multicolumn{1}{c}{ Region } & \# Municipalities sampled & \# Firms sampled & Response (\%) \\
\hline Amsterdam & 16 & 5980 & $399(6.7 \%)$ \\
Rotterdam & 28 & 4818 & $357(7.4 \%)$ \\
Groningen & 12 & 2128 & $167(7.8 \%)$ \\
Eindhoven & 16 & 3763 & $289(7.7 \%)$ \\
Apeldoorn & 14 & 2217 & $162(7.3 \%)$ \\
Arnhem & 24 & 3259 & $271(8.3 \%)$ \\
The Hague & 13 & 3117 & $185(5.9 \%)$ \\
Utrecht & 13 & 3355 & $179(5.3 \%)$ \\
TOTAL & 136 & 28637 & $2009(7.0 \%)$ \\
\hline
\end{tabular}

Our size measure is designed to capture our collection of highly heterogeneous firms. We used the gross sales of the firm in the 2004 as our size measure. This measure is commonly considered the most applicable size measure in cross-industry research (Cohen and Klepper 1996). Job density was used as an indicator of urbanization externalities stemming from a large concentration of economic activity. We used density rather than the absolute number of jobs to correct for differences in geographical size between municipalities. Urbanization economies were thus measured by a density indicator reflecting the number of total jobs per square kilometer within the responding firm's municipality. Economies of specialization were measured by the location quotient for the region and industry in which the responding firm was active (based on its 2-digit SIC code) in the year 2002. In all models, we included industry fixed effects to control for differences between industries that are not captured by our main effects. We included industry dummies at the 2-digit SIC level.

\subsection{Modeling Results}

The results are presented in table 5. Model 1 shows two firm-level characteristics with a direct effect on firm performance. It shows that the performance effect is positive, but with diminishing returns for firm size. Model 2 reveals that the two region-level variables (i.e., 
urbanization and specialization) have no effect on firm productivity when examining their direct effect in isolation. Model 3 illustrates that the findings of models 1 and 2 remain unchanged when firm- and region-level variables are included simultaneously. Model 4, however, shows that the picture changes drastically when cross-level interaction effects are included. The model fit improves significantly at both the firm and the region level, and many interesting effects are revealed. Due to their non-linear nature, these interaction effects are extremely difficult to interpret based on table 5. Therefore, the combinations of firm- and region-level variables for which significant interaction effects were found are presented in figures 3 and 4.

Table 5 Hierarchical Multilevel Regression Models of Firm Productivity

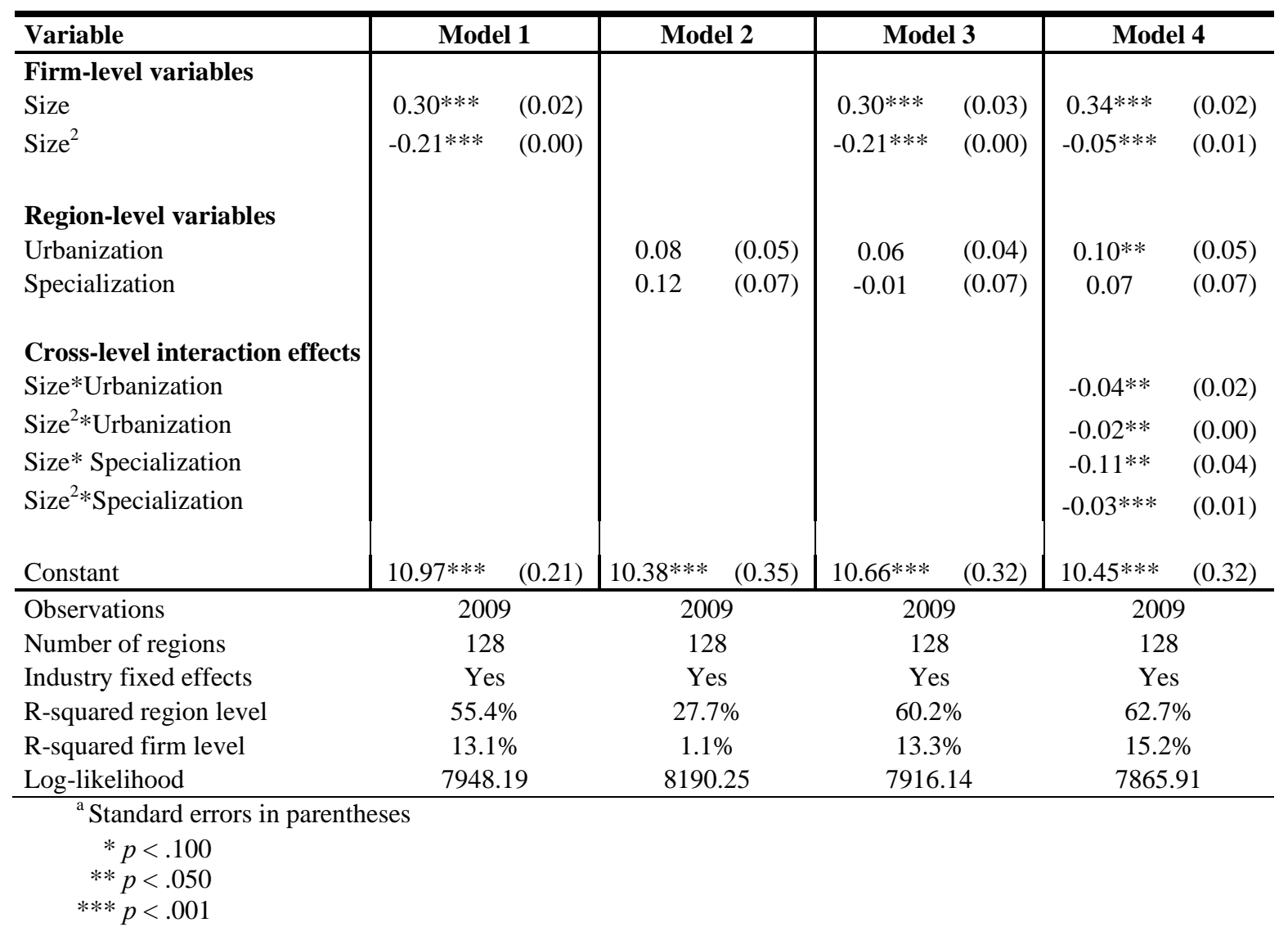


Figure 3: Multilevel interaction between firm size and urbanization effects

Figure 3a

Figure 3b

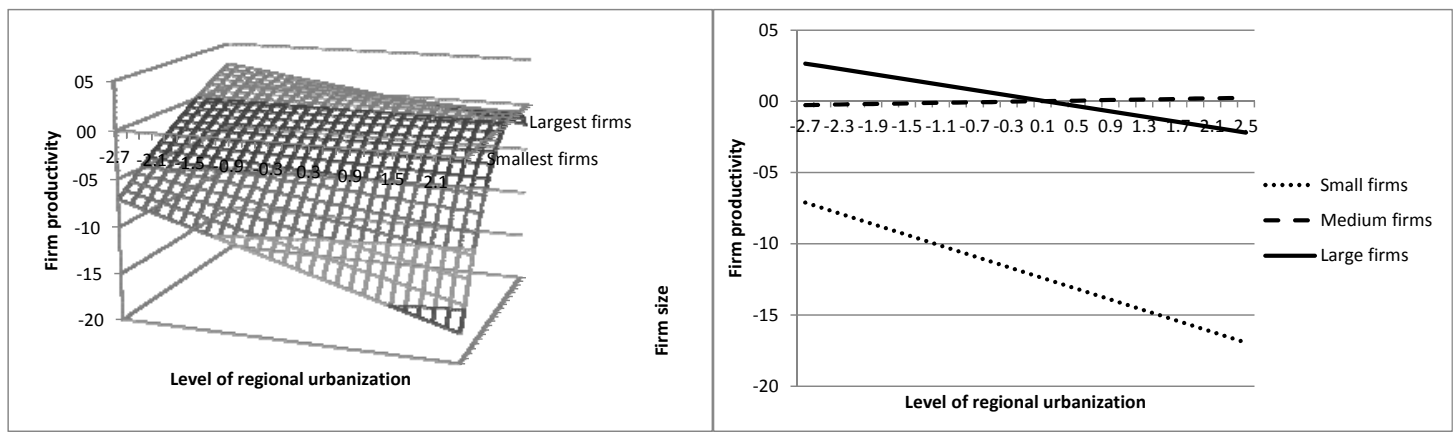

Figure 4: Multilevel interaction between firm size and specialization effects

Figure 4a

Figure $4 b$

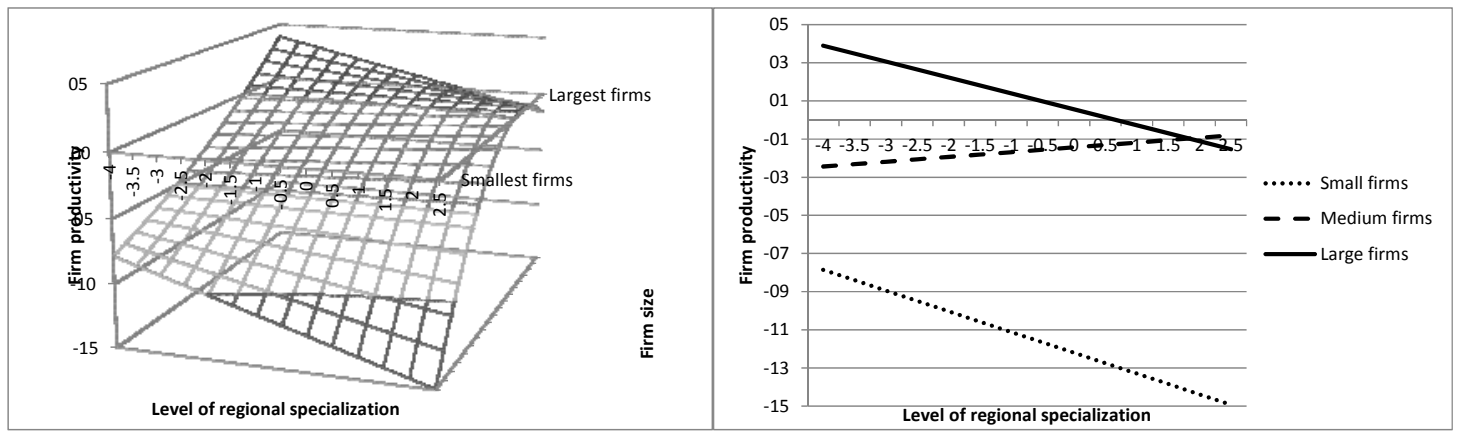

Figure 3 presents the interaction effect between urbanization and firm size. Figure 3a presents the productivity effects of the range of combinations between the two variables, and figure $3 \mathrm{~b}$ presents the relationship between urbanization and performance for three selected levels of firm size. The figure clearly reveals that the relation between urbanization and performance is qualitatively different for different levels of firm size. In line with our hypothesis, the relationship is positive for medium-sized firms but negative for small and large firms. The relationship is significantly more negative for small firms compared to large firms. Figure 4 presents the interaction effect between specialization and firm size. Again, in line with our hypothesis, the relationship between the agglomeration effect and firm productivity is positive for medium-sized firms but negative for small and large firms. However, in this 
instance, the strength of the negative relation does not significantly differ between large and small firms. If some firms experience a negative performance effect and others experience a positive effect from co-location and agglomeration, the total regional effect is dependent on the composition and structure of the region. This explains why, on a regional level, as noted in section 1, outcomes of agglomeration economies and growth potentials can be ambiguous.

\section{Conclusion}

A large body of empirical literature examines whether spatial circumstances give rise to agglomeration economies, external economies from which firms can benefit through colocation, which endogenously induce localized economic growth. Many empirical studies show that agglomeration economies may be one source of the uneven distribution of economic activities and economic growth across cities and regions. At the same time, little is known about the importance of agglomeration economies for the performance of firms. This absence is remarkable because the theories that underlie agglomeration economies are microeconomic in nature. Agglomeration economies do not directly foster regional economic growth; they do so indirectly through their effect on firm performance.

In this paper, we have shown that multilevel analysis provides an analytical tool to assess the extent to which a link exists between the macro level and the micro level. As Corrado and Fingleton (2011, p.29) note, "Hierarchical models are almost completely absent from the spatial econometrics literature (and vice-versa are spatial econometric models mostly absent from the multilevel literature, for an exception see Steenbeek et al. 2012), but hierarchical models represent one major alternative way of capturing spatial effects, focusing on the multilevel aspects of causation that are a reality of many spatial processes. Recognition of the different form of interactions between variables which affect each individual unit (firm) of the system and the groups they belong to has important empirical implications”. Multilevel models offer a natural way to assess contextuality. Applying multilevel analysis to empirical work on agglomeration begins with the simple observation that firms sharing the same external environment are more similar in their performance than firms that do not share the same external environment. This is due to shared agglomeration externalities. Thus, we assessed the extent to which variance in the survival and growth rates of new firms (case study 1) and firm-level productivity (case study 2) can be attributed to between-firm variance, between-area variance, or between-sector variance. Using multilevel analysis, we are able to assign variability to the appropriate context. Multilevel analysis 
allows us to incorporate unobserved heterogeneity into the model by including random intercepts and allowing relationships to vary across contexts through the inclusion of random coefficients. Whereas "standard" regression models are designed to model the mean, multilevel analysis focuses on modeling variances explicitly. For example, the effect of urbanization and localization externalities may vary across small and large firms (case study 2) or across sectors simultaneously with spatial levels (case study 1). This kind of complexity can be captured in a multilevel framework through the inclusion of random coefficients.

Our two case studies show that cross-level interactions and cross-classified (multiplemembership) variants of the multilevel model have considerable advantages over other estimation methods (e.g., spatial econometrics) in capturing the firm- and context-level heterogeneity in firm performance. However, there are some limitations to the use of multilevel analysis in spatial research. Most importantly, multilevel analysis does not fully account for the spatial dependence present in data in that it does not allow for the effect of neighboring regions on the performance of a firm. Spatial spillover effects between regions may be highly relevant, and failing to account for these effects may underestimate the importance of 'space' in the performance of firms (Corrado and Fingleton 2011). For example, R\&D and human capital are well known for their spatial spillover effects. Viable solutions would be to include spatially weighted independent variables in the model (e.g., Florax and Folmer 1992), to use a conditional autoregressive multilevel model (e.g., Breslow and Clayton 1993) or to employ a spatial multiple membership model (e.g., Browne et al. 2001). Combining such empirical strategies with a micro-macro framework will advance the literature on agglomeration economics in its effort to determine the extent to which the agglomerated environment of firms is important for their performance.

\section{References}

Acs, Z. and Armington, C. (2004) The impact of geographic differences in human capital on service firm formation rates. Journal of Urban Economics 56: 244-278.

Alker, H.R. (1969), A typology of ecological fallacies. In: Dogan M, Rokan S (eds) Quantitative ecological analysis. MIT Press, Cambridge, MA, pp 69-86.

Andersson, M. and Lööf, H. (2011) Agglomeration and productivity: evidence from firmlevel data. Annals of Regional Science 46: 601-620. 
Arbia, G. (2001) Modelling the geography of economic activities in a continuous space. Papers in Regional Science 80: 411-423.

Arikan, A.T. (2009) Interfirm knowledge exchanges and the knowledge creation capability of clusters. Academy of Management Review 34: 658-676.

Arikan, A.T. and Schilling, M.A. (2011) Structure and governance in industrial districts: implications for competitive advantage. Journal of Management Studies 48: 772-803.

Audretsch, D.B. and Dohse, D. (2007) Location: a neglected determinant of firm growth. Review of World Economics 143: 79-107.

Audretsch, D.B. and Mata, J. (1995) The post-entry performance of firms: introduction. International Journal of Industrial Organization 14: 413-419.

Baldwin, R. and Okubu, T. (2006) Heterogeneous firms, agglomeration economies and economic geography. Journal of Economic Geography 6: 323-346.

Baldwin, R., Beckstead, D., Brown, W.M., Rigby, D.L. (2008) Agglomeration and the geography of localization economies in Canada. Regional Studies 42: 117-132.

Beaudry, C. and Schiffauerova, A. (2009) Who's right, Marshall or Jacobs? The localization versus urbanization debate. Research Policy 38: 318-337.

Bell, G.G. (2005) Clusters, Networks, and Firm Innovativeness. Strategic Management Journal 26: 287-296.

Beugelsdijk, S. (2007) The regional environment and a firm's innovative performance: A plea for a multilevel interactionist approach. Economic Geography 83: 181-199.

Brakman, S., Garretsen, H. and Van Marrewijk, C. (2009), The new introduction to geographical economics. Cambridge: Cambridge University Press.

Breslow, N.E. and Clayton, D.G. (1993) Approximate inference in generalised linear models. Journal of the American Statistical Association 88: 9-25.

Briant, A., Combes, P.P. and Lafourcadem, M. (2010) Dots to boxes: Do the size and shape of spatial units jeopardize economic geography estimations? Journal of Urban Economics 67: 287-302.

Browne, W.J., Goldstein, H. and Rasbash, J. (2001) Multiple membership multiple classification (MMMC) models. Statistical Modelling 1: 103-124.

Brülhart, M. and Mathys, N.A. (2008) Sectoral agglomeration economies in a panel of European regions. Regional Science and Urban Economics 38: 348-362.

Brülhart M. and Traeger, R. (2005) An account of geographic concentration patterns in Europe. Regional Science and Urban Economics 35: 597-624. 
Bullen, N., Jones, K. and Duncan, C. (1997) Modelling complexity: analysing betweenindividual and between-place variation - a multilevel tutorial. Environment and Planning A 29: 585-609.

Cohen, W.M. and Klepper, S. (1996) Firm size and the nature of innovation within industries: The case of process and product R\&D. The Review of Economics and Statistics 78: 232-243.

Coleman, J.S. (1990) Foundations of social theory . Harvard University Press, Cambridge, MA.

Combes, P.P. (2000) Economic structure and local growth: France 1984-1993. Journal of Urban Economics 47: 329-355.

Combes P.P., Duranton, G. and Gobillon, L. (2008) Spatial wage disparities: sorting matters. Journal of Urban Economics 63: 723-742.

Corrado, L. and Fingleton, B. (2011), Where is the economics in spatial econometrics? SERC Discussion Paper 71, London: LSE.

Deeds, D.L. and Rothaermel, F.T. (2003) Honeymoons and Liabilities: The Relationship between Age and Performance in Research and Development Alliances. Journal of Product Innovation Management 20: 468-484.

De Groot, H.F.L., Poot, J. and Smit, M.J. (2009), Agglomeration externalities, innovation and regional growth: theoretical reflections and meta-analysis. In: Capello, R. and Nijkamp, P. (eds) Handbook of Regional Growth and Development Theories. Edward Elgar, Cheltenham, UK, Chapter 14.

Dicken, P. and Malmberg, A. (2001), Firms in territories: a relational perspective. Economic Geography 77: 345-363.

Duranton, G. and Overman, H.G. (2005), Testing for localization using micro-geographic data. Review of Economic Studies 72: 1077-1106.

Duranton, G. and Puga, D. (2000) Diversity and specialisation in cities: why, where and when does it matter? Urban Studies 37: 533-555.

Florax, R. and Folmer, H. (1992) Specification and estimation of spatial linear panel models: Monte Carlo evaluation of pre-test estimators. Regional Science and Urban Economics 22: 402-432.

Frenken K., Van Oort, F.G. and Verburg, T. (2007), Related variety, unrelated variety and economic growth. Regional Studies 41: 685-697. 
Geroski, P.A. (1995) What do we know about entry? International Journal of Industrial Organization 13: 421-440.

Glaeser, E.L., Kallal, H.D., Scheinkman, A. and Shleifer, A. (1992) Growth in cities. Journal of Political Economy 100: 1126-1152.

Goldstein, H. (2003) Multilevel Statistical Models, $3^{\text {rd }}$ edtion. Edward Arnold, London.

Goldstein, H. and Rashbash, J. (1996) Improved approximations for multilevel models with binary responses. Journal of the Royal Statistical Society (A) 159: 505-513.

Gordon, I.R, and McCann, P. (2000) Industrial clusters: complexes, agglomeration, and/or social networks? Urban Studies 37: 513-532.

Grabher, G. (1993) Rediscovering the scoial in the economics of interfirm relations. In: Grabher, G. (ed.) The embedded firm. On the socioeconomics of interfirm relations. Routledge, London, pp. 1-33.

Granovetter, M.S. (1985) Economic action and social structure: the problem of embeddedness. American Journal of Sociology 81: 481-510.

Harrison, B., Kelley, M.R. and Gant, J. (1997) Innovative firm behavior and local milieu: exploring the intersection of agglomeration, firm effects, and technological change. Economic Geography 72: 233-258.

Henderson J.V. (2003) Marshall’s scale economies. Journal of Urban Economics 53: 1-28.

Henderson, J.V., Kuncoro, A. and Turner, M. (1995) Industrial development in cities. Journal of Political Econmy 103: 1067-1085.

Hoover, E.M. (1948) The Location of Economic Activity. McGraw Hill, New York.

Hox, J.J. (2002) Multilevel analysis: techniques and applications. Erlbaum, Mahwah, NJ.

Isard, W. (1956) Location and space-economy. MIT Press, Cambridge, MA.

Jones, K. (2004), An introduction to statistical modelling. In: Somekh B, Lewin C (eds) Research methods in the social sciences. Sage, London, pp. 236-251.

Knoben, J. (2011). The geographical distance of relocation search: An extended resource based perspective. Economic Geography, 87: 371-392.

Knoben J. and Oerlemans L.A.G. (2006) Proximity and inter-organizational collaboration: A literature review. International Journal of Management Reviews 8: 71-89.

Kogut, B. and Zander U. (1992) Knowledge of the Firm, Combination Capabilities and the Replication of Technology. Organization Science 3: 383-397.

Lucas, R.E. (1988), On the mechanics of economic development. Journal of Monetary Economics 22: 3-42. 
Macintyre, S., MacIver, S. and Sooman, A. (1993) Area, class and health: should we be focusing on places or people? Journal of Social Policy 22: 213-234.

Marshall, A. (1890) Principles of economics. MacMillian, London.

Martin, P. and Ottaviano, J.P. (2001) Growth and agglomeration. International Economic Review 42: 947- 968.

Martin, P., Mayer, T. and Mayneris, F. (2011), Spatial concentration and firm-level productivity in France. Journal of Urban Economics 69: 182-195.

McCann, P. and Van Oort, F.G. (2009), Theories of agglomeration and regional economic growth: a historical review. In: Capello, R. and Nijkamp, P. (eds) Handbook of Regional Growth and Development Theories. Edward Elgar, Cheltenham: 19-32.

McCann, B.T. and Folta, T.B. (2008). Location matters: where we have been and where we might go in agglomeration research. Journal of Management 34: 532-565.

McCann, B.T. and Folta, T.B. (2011) Performance differentials within geographic clusters. Journal of Business Venturing 26: 104-123.

McGahan, A.M. and Porter, M.E. (1997), How much does industry matter really? Strategic Management Journal 18: 15-30.

Melo, P.C., Graham, D.J. and Noland, R.B. (2008), A meta-analysis of estimates of agglomeration economies, Regional Science and Urban Economics 39: 332-342.

Miller, D. and Chen, M.J. (1994) Sources and consequences of competitive inertia - a study of the United-States airline industry. Administrative Science Quarterly 39: 1-23.

Mion, G. and Naticchioni, P. (2009), The spatial sorting and matching of skills and firms. Canadian Journal of Economics 42: 28-55.

Moon, G., Subramanian, S.V., Jones, K., Duncan, C. and Twigg, L. (2005) Area-based studies and the evaluation of multilevel influences on health outcomes. In: Bowling, A. and Ebrahim, S.(eds) Handbook of health services research - investigation, measurement and analysis. Open University Press, Berkshire, pp. 262-296.

Mundlak, Y. (1978) On the pooling of time series and cross-section data. Econometrica 46: 69-85.

Ohlin, B. (1933) Interregional and international trade. Harvard University Press, Cambridge, MA.

Ottaviano, G.P. (2011) 'New' New Economic Geography: firm heterogeneity and agglomeration economies. Journal of Economic Geography 11: 231-240. 
Puga, D. (2010) The magnitude and causes of agglomeration economies. Journal of Regional Science 50: 203-219.

Quigley, J.M. (1998) Urban diversity and economic growth. Journal of Economic Perspectives 12: $127-138$.

Raspe, O. and Van Oort F.G. (2011) Growth of new firms and spatially bounded knowledge externalities. Annals of Regional Science 46: 495-518.

Renski, H. (2011) External economies of localization, urbanization and industrial diversity and new firm survival. Papers in Regional Science 90: 473-502.

Robinson, W.S. (1950) Ecological correlations and the behavior of individuals. Sociological Review 15: 351-357.

Romer, P.M. (1986) Increasing returns and long-run growth. Journal of Political Economy 94: 1002-1037.

Rosenthal, S.S. and Strange, W.C. (2003) Geography, industrial organization, and agglomeration. Review of Economics and Statistics 85: 377-393.

Rosenthal, S.S. and Strange, W.C. (2004), Evidence on the nature and sources of agglomeration economies. In: Henderson, J.V. and Thisse, J.F. (eds) Handbook of regional and urban economics: cities and geography, Volume 4. North Holland, Amsterdam: 2119-2179.

Shaver, J.M. and Flyer, F. (2000) Agglomeration Economies, Firm Heterogeneity, and Foreign Direct Investment in the United States. Strategic Management Journal 21: 1175-1193.

Snijders T.A.B. and Berkhof, J. (2007) Diagnostic checks for multilevel models. In: De Leeuw, J. and Meijer, E. (eds) Handbook of Multilevel Analysis. Springer, New York, pp. 139-173.

Snijders T.A.B. and Bosker, R.J. (1999) Multilevel analysis: an introduction to basic and advanced multilevel modelling. Sage, London.

Steenbeek, W., Volker, B., Flap, H. and Van Oort, F.G. (2012), Local business as attractors or preventers of neighborhood disorder. Journal of Research in Crime and Delinquency (forthcoming).

Tallman, S., Jenkins, M., Henry, N. and Pinch, S. (2004) Knowledge, clusters, and competitive advantage. Academy of Management Review 29: 258-271.

Taylor, M. and Asheim, B. (2001) The concept of the firm in economic geography. Economic Geography 77: 315-328. 
Van Oort, F.G. (2007) Spatial and sectoral composition effects of agglomeration economies.

Papers in Regional Science 86: 5-30.

\footnotetext{
${ }^{\mathrm{i}}$ The sectors in advanced producer services in our study include publishing, banks and insurance, financial services, real estate activities, rental and leasing, computer services, information services, accounting, legal services, market research, advertising, management consulting, architectural and engineering activities, telecommunications, office administration and business support activities.

${ }^{\text {ii }}$ Models 3 to 6 are estimated using a restricted iterative generalized least squares estimation (RIGLS) and a second-order PQL estimation (Breslow and Clayton 1993, Goldstein and Rasbash 1996). The standard model assumes that the establishment-level predictor variables are uncorrelated with the club- and regional-level error terms and that the club-level predictor variables are uncorrelated with the regional-level error terms. However, both theoretically and empirically, such an assumption is difficult to meet. Not correcting for this would lead to inconsistent parameter estimates. As shown by Snijders and Berkhof (2007), the correlation between the lowerlevel predictor variables and higher-level error terms can be easily removed by including club- or region-level means of the lower-level predictor variables in the regression model, a procedure known as the Mundlak (1978) correction. Hence, our multi-level probit models are augmented with this correction.

iii Because we estimated survival and growth, the latter analysis faces the problem of panel attrition by nonsurvival. Firms that do not survive inhibit information on the missing dependent variable. Possible disturbances in the estimations of the growth coefficients related to this selection bias occur when characteristics of nonsurvival are related to firm growth. An effective way to control for this selection bias is to apply a two-step Heckman procedure, including a correction factor that reflects the effects of all unmeasured characteristics related to firm survival and captures the part of the non-survivors effect that is related to growth. The use of an instrument variable in the survival analysis is highly relevant. This variable should relate to non-survival, but not to growth. Because both phenomena are often considered 'in line with one another', it is difficult to find appropriate instruments. We tested for the average regional number of bankruptcies (1994-2006), a sectoral 'new economy' variable (Audretsch and Dohse 2007), and for individual-level size-quadrat specifications. One can hypothesize that they have an effect on survival, but not on growth per se (Raspe and Van Oort 2011). The test gave us insight into the fact that controlling for selection bias does not improve the models significantly (although the instruments can be significant, the correction factor is not significant or is only slightly significant). Because the focus in our paper is on the multilevel research framework and multilevel modeling (variance decomposition insights), we have chosen not to present the Heckman models. Instead, we only show the results of the probit multilevel regressions without correction for panel attrition.

${ }^{\text {iv }}$ In our sample, we included only firms with more than one employee. The reason for this choice was that the Netherlands is characterized by an extremely large number of self-employed people without personnel (well over a million in a labor force of less than eight million) who register their "businesses" at their home addresses. However, these self-employed people do not truly own a business establishment; rather, they work for (sometimes several) larger organizations. The reasons for registering as self-employed are largely related to tax and social security benefits. As such, including this group of firms in our sample would bias our results.
} 